\title{
Capacities and Limitations of Wind Tunnel Physical Experiments on Motion and Dispersion of Different Density Gas Pollutants
}

\author{
Ondřej Zavila ${ }^{1}$, Tomáš Blejchař ${ }^{2}$ \\ ${ }^{1}$ Department of Fire Protection, Faculty of Safety Engineering, VŠB - Technical University of Ostrava, Lumirova 13/630, \\ Ostrava - Výškovice, 700 30, Czech Republic,ondrej.zavila@vsb.cz \\ ${ }^{2}$ Department of Hydrodynamics and Hydraulic Equipment, Faculty of Mechanical Engineering, VŠB - Technical University \\ of Ostrava, 17. listopadu 15, Ostrava-Poruba, 708 33, Czech Republic
}

\begin{abstract}
The article focuses on the analysis of the possibilities to model motion and dispersion of plumes of different density gas pollutants in lowspeed wind tunnels based on the application of physical similarity criteria, in this case the Froude number. The analysis of the physical nature of the modeled process by the Froude number is focused on the influence of air flow velocity, gas pollutant density and model scale. This gives an idea of limitations for this type of physical experiments in relation to the modeled real phenomena. The resulting statements and logical links are exemplified by a CFD numerical simulation of a given task calculated in ANSYS Fluent software.
\end{abstract}

Keywords: Physical similarity, aerodynamic tunnel, Froude number, CFD, gas pollutant.

\section{INTRODUCTION}

Air pollution is becoming an increasingly serious global issue. Factories produce large amounts of pollutants that damage the environment and harm human health. From this point of view, problems of motion and dispersion of pollutants in the atmosphere relate not only to environmental studies but also to other disciplines, such as safety engineering.

An understanding of the physical principles of pollutants' motion and dispersion is important in order to determine the impact of air pollution on the environment and humans. This study only deals with the physical principles of pollutants' motion and dispersion. Possible chemical reactions in the atmosphere are not covered.

For the purpose of the study, a simple model of a typical real situation was defined. Physical parameters of the model were gradually modified to achieve visible changes in results so that general principles could be defined. The above-mentioned demonstration model represents a chimney situated in a simple flat terrain. Gas pollutant is discharged from the chimney and carried by flowing air. Gas pollutant plume is detected and visualized with a numerical model as iso-surfaces or contours of pollutant concentrations in twodimensional cut planes of three-dimensional geometry.

The dependence of the pollutant plume shape, size and inclination on modification of three physical parameters was investigated. The selected parameters included pollutant density, air flow velocity and model scale.
The results are presented in the form of text and commented figures. ANSYS Fluent 15.0 CFD (Computational Fluid Dynamics) code was used to demonstrate and visualize all problem variants (see [1], [2]). The numerical model of the pollutant plume motion created in this software was verified by an experiment conducted in the low-speed wind tunnel in the Aerodynamic Laboratory of the Academy of Sciences of the Czech Republic in Novy Knin (see [3], [4], [5]). The maximum difference between experiment data and numerical simulation data sets was one order (for more details see [6]). One of the aims of the study is also to demonstrate that physical modeling of pollutant plume motion and dispersion with severely downscaled models has its limitations that should be known and considered to avoid obtaining false results.

\section{SUBJECT \& METHODS}

\section{A. Physical similarity}

Two phenomena can be considered to be similar (despite different geometrical scales) if three types of similarity match: geometric, kinematic, and dynamic. Criteria of geometric similarity require that the ratios of main corresponding dimensions on the model and the original pattern be constant. Also, main corresponding angles on the original pattern and the model must be of the same value. Criteria of kinematic similarity require that the ratios of velocities at corresponding points be the same for both the 
original pattern and the model. Criteria of dynamic similarity require that the ratios of the main forces at corresponding points be the same for both the original pattern and the model.

Forces can be divided into two groups: areal forces and volume (weight) forces. Areal forces include friction forces, compression forces, and capillary (surface) forces. Volume (weight) forces include inertial forces, gravity forces, and impulse forces (resulting from the change in momentum). According to the type of phenomena, these forces can be put into mathematical relation and criteria (numbers) of similarity can be established. In fluid mechanics, the Reynolds number, Euler number, Newton number, Froude number, Weber number, and Mach number are the most widely known criteria. Each of them expresses ratio between two different forces. In practice, it is not possible to achieve correspondence between the original pattern and the model in all criteria. Therefore, it is always up to the investigators who must use their knowledge and experience to choose the right and most important criterion (or criteria) for the investigated phenomenon. As a result, investigators usually work with one or two dominant criteria of similarity [7], [8], [9].

\section{B. Froude number}

The Froude number expresses the ratio between gravity forces and inertial forces. Gravity forces cause vertical movements of the plume (climbing or descending) and inertial forces cause horizontal movements of the plume. The Froude number can be therefore considered as a criterion of dynamic similarity, which should be of the same value for both the scaled model and the real pattern (see [7], [8], [9]).

The Froude number can be defined as

$$
\begin{gathered}
F r \approx \frac{F_{I-\text { air }}}{F_{G-\text { pollutant }}}=\frac{\rho_{\text {air }} \cdot S \cdot v_{\text {air }}{ }^{2}}{\rho_{\text {pollutant }} \cdot g \cdot V}= \\
=\frac{\rho_{\text {air }} \cdot l_{2} \cdot l_{3} \cdot v_{\text {air }}{ }^{2}}{\rho_{\text {pollu tant }} \cdot g \cdot l_{1} \cdot l_{2} \cdot l_{3}}=\frac{\rho_{\text {air }} \cdot v_{\text {air }}{ }^{2}}{\rho_{\text {pollutant }} \cdot g \cdot l_{1}}
\end{gathered}
$$

where $F_{I \text {-air }}$ is the inertial force due to the air acting on pollutant element [N], $F_{G \text {-pollutant }}$ is the gravity force acting on pollutant element $[\mathrm{N}], \rho_{\text {air }}$ is the air density $\left[\mathrm{kg} / \mathrm{m}^{3}\right], \rho_{\text {pollutant }}$ is the pollutant density $\left[\mathrm{kg} / \mathrm{m}^{3}\right], \quad S$ is the surface of pollutant element acted on by the flowing air $\left[\mathrm{m}^{2}\right], v_{\text {air }}$ is the air flow velocity $[\mathrm{m} / \mathrm{s}], g$ is the gravity acceleration constant $\left[\mathrm{m} / \mathrm{s}^{2}\right], V$ is the volume of pollutant element released from the pollutant source per 1 second $\left[\mathrm{m}^{3}\right], \quad l_{1}$ is the $1^{\text {st }}$ characteristic dimension of the pollutant source (length of pollutant cubic element) [m], $l_{2}$ is the $2^{\text {nd }}$ characteristic dimension of the pollutant source (width of pollutant cubic element) $[\mathrm{m}]$ and $l_{3}$ is the $3^{\text {rd }}$ characteristic dimension of the pollutant source (height of pollutant cubic element) $[\mathrm{m}] . \quad l_{3}$ can be replaced by $v_{\text {pollutant }}$ that represents the velocity of the pollutant released from the source in vertical direction $[\mathrm{m} / \mathrm{s}] . F r$ is a dimensionless constant [-] whose value determines whether the inertial force or the gravity force will dominate in the specific pollutant plume motion scenario.

Important characteristics are illustrated in Fig.1. Pollutant element was simplified into a rectangular cuboid with dimensions of $l_{1}, l_{2}$ and $l_{3}$ to make practical calculations easier. Of course, the spout of a real chimney can be of a different shape, most commonly circular or elliptical. In this case, it is advisable to calculate the surface of the spout and transform the shape into a square or a rectangle with dimensions of $l_{1}$ and $l_{2}$. The value of $l_{3}$ remains the same (despite the shape of the spout) and is replaced by the velocity with which the pollutant leaves the source in vertical direction $v_{\text {pollu tant }}$.

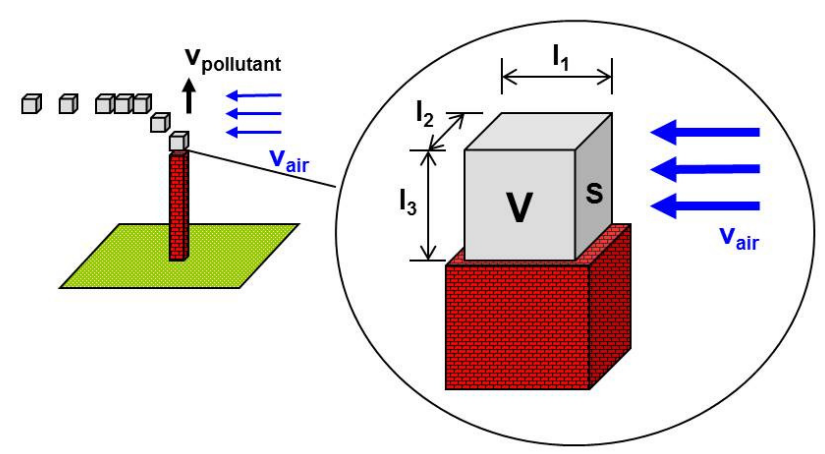

Fig.1. Air flow action on gas pollutant element leaking from the nozzle (chimney).

If $F r<1$, gravity forces are assumed greater than inertial forces. Hence, vertical motions (climbing or descending) of the gas pollutant plume can be expected due to different densities of the pollutant and the air. Plumes of light gas pollutants will tend to climb, whereas plumes of heavy gas pollutants will tend to descend.

If $F r=1$, gravity forces are assumed equal to inertial forces. Hence, gas pollutant plumes are carried by flowing air along with manifesting partial vertical motions.

If $F r>1$, inertial forces are assumed greater than gravity forces. Hence, vertical motions of the gas pollutant plume are limited or nonexistent. The gas pollutant plume is carried by strong flowing air, regardless of the pollutant - air density difference or weight of the pollutant.

This third scenario causes common difficulties when planning gas pollutant plume motion and dispersion experiments with downscaled models in low-speed wind tunnels. At small dimensions of measuring sections of common wind tunnels and, thus, low scales of models, the air flow may be too great to allow vertical motions of gas pollutant plumes. Proper conditions often cannot be assured in such cases. 
C. Calculation of air flow velocity for inertial and gravity forces maintained in balance $(\mathrm{Fr}=1)$

According to (1), the air flow velocity $v_{\text {air }}$ influences the inertial force $F_{I \text {-air }}$ that causes gas pollutant horizontal motion. If all the other physical characteristics are constant, the following principles can be formulated: The greater is the air flow velocity $v_{\text {air }}$, the greater is the inertial force $F_{I \text {-air }}$. The greater is the inertial force, the more limited are the pollutant plume vertical motions (climbing or descending).

The air flow velocity $v_{\text {air }, F r=1}$ for $F r=1$ (i.e., inertial and gravity forces are equal) can be deduced from (1):

$$
\begin{gathered}
1=\frac{F_{I-\text { air }}}{F_{G-\text { pollu tant }}}=\frac{\rho_{\text {air }} \cdot S \cdot v_{\text {air }, F r=1}^{2}}{\rho_{\text {pollu tant }} \cdot g \cdot V}= \\
=\frac{\rho_{\text {air }} \cdot l_{2} \cdot l_{3} \cdot v_{\text {air }, F r=1}^{2}}{\rho_{\text {pollu tan } t} \cdot g \cdot l_{1} \cdot l_{2} \cdot l_{3}}=\frac{\rho_{\text {air }} \cdot v_{\text {air }, F r=1}^{2}}{\rho_{\text {pollu tant }} \cdot g \cdot l_{1}}
\end{gathered}
$$

Thus, the air flow velocity $v_{\text {air }, F r=1}$ is

$$
\begin{gathered}
v_{\text {air }, \mathrm{Fr}=1}=\sqrt{\frac{\rho_{\text {pollu tant }} \cdot g \cdot l_{1}}{\rho_{\text {air }}}}= \\
=\sqrt{\frac{\rho_{\text {pollu tant }} \cdot g \cdot l_{1} \cdot l_{2} \cdot l_{3}}{\rho_{\text {air }} \cdot l_{2} \cdot l_{3}}}=\sqrt{\frac{\rho_{\text {pollu tant }} \cdot g \cdot V}{\rho_{\text {air }} \cdot S}}
\end{gathered}
$$

However, one must realize that the change in air flow velocity influences also air flow field turbulent characteristics. For example, turbulent intensity is influenced when the air flows around solid objects or in a complex terrain. Investigators must consider whether these changes have a serious impact on accuracy of the experiment or mathematical model. This is very important for modeling gas pollutant motion and dispersion in a complex geometry (complex terrain) where the real model of turbulent flow field is the key element of the simulation. If the air turbulent flow field is seriously influenced by the change in the air flow velocity, the results of the analysis can be misleading. This approach is therefore not suitable for such cases and a different parameter of the model must be changed.

\section{Calculation of pollutant density for inertial and gravity} forces maintained in balance $(F r=1)$

According to (1), the pollutant density $\rho_{\text {pollutant }}$ influences the gravity force $F_{G \text {-pollutant }}$ that causes gas pollutant vertical motions (climbing or descending). If all the other physical characteristics are constant, the following principles can be formulated: If the pollutant density $\rho_{\text {pollu tant }}$ is greater than the air density $\rho_{\text {air }}$, the pollutant tends to descend (i.e., the gas pollutant plume descends). If the pollutant density $\rho_{\text {pollu tant }}$ is lower than the air density $\rho_{\text {air }}$, the pollutant tends to climb (i.e., the gas pollutant plume climbs). The greater are the gravity forces $F_{G-\text { pollutant }}$, the more significant are the gas pollutant plume vertical movements (climbing or descending).

The pollutant density $\rho_{\text {pollutant }, F r=1}$ for $F r=1$ (i.e., inertial and gravity forces are equal) can be deduced from (1):

$$
\begin{gathered}
1=\frac{F_{I-\text { air }}}{F_{G-\text { pollutant }}}=\frac{\rho_{\text {air }} \cdot S \cdot v_{\text {air }}{ }^{2}}{\rho_{\text {pollutant }, F r=1} \cdot g \cdot V}= \\
=\frac{\rho_{\text {air }} \cdot l_{2} \cdot l_{3} \cdot v_{\text {air }}{ }^{2}}{\rho_{\text {pollu tan }, F r=1} \cdot g \cdot l_{1} \cdot l_{2} \cdot l_{3}}=\frac{\rho_{\text {air }} \cdot v_{\text {air }}{ }^{2}}{\rho_{\text {pollu tant }, F r=1} \cdot g \cdot l_{1}}
\end{gathered}
$$

Thus, the pollutant density $\rho_{\text {pollu tan } t, F r=1}$ is

$$
\begin{aligned}
\rho_{\text {pollu tan }, F r=1}= & \frac{\rho_{\text {air }} \cdot v_{\text {air }}{ }^{2}}{g \cdot l_{1}}=\frac{\rho_{\text {air }} \cdot v_{\text {air }}{ }^{2} \cdot l_{2} \cdot l_{3}}{g \cdot l_{1} \cdot l_{2} \cdot l_{3}}= \\
& =\frac{\rho_{\text {air }} \cdot v_{\text {air }}{ }^{2} \cdot S}{g \cdot V}
\end{aligned}
$$

A change in pollutant density in order to achieve the optimum ratio between inertial and gravity forces would be often the ideal solution. However, there is a problem. The densities of pollutants range within a narrow interval approximately of one order of magnitude - which is usually not enough to compensate the Froude number differences resulting from, e.g., a substantial change of the model scale.

A typical example can be the physical modeling of gas pollutant plumes in low-speed wind tunnels where the scale of the model is around 1:1000. In such a case, there is a need to change the pollutant density 100 , or even 1000 times, which is impossible. This is why change in pollutant density can be used to achieve only a small change in the Froude number. These small changes, however, may not be sufficient for a successful execution of the experiment or numerical modeling.

The change of the flowing gas density could be an alternative solution. For example, air could be replaced by a different gas with a different value of density. However, this change influences turbulent flow field characteristics, which may be undesirable.

\section{E. Calculation of model scale for inertial and gravity forces maintained in balance $(\mathrm{Fr}=1)$}

According to (1), the model scale can be expressed by using the value $l_{1}$ that represents the $1^{\text {st }}$ characteristic dimension of the pollutant source (i.e., length of pollutant 
cubic element). The model scale influences both inertial and gravity forces and changes their ratio. If all the other physical characteristics are constant, the following principles can be formulated: The greater is the model scale, the greater is the influence of gravity forces. The smaller is the model scale, the greater is the influence of inertial forces. Gravity forces are, e.g., greater in a model scaled at $1: 4$ than in one scaled at $1: 1000$.

The value of the $1^{\text {st }}$ characteristic dimension of the pollutant source (length of pollutant cubic element) $l_{1, F r=1}$

for $F r=1$ (inertial and gravity forces are equal) can be deduced from (1):

$$
\begin{aligned}
1 & =\frac{F_{I-\text { air }}}{F_{G-\text { pollu tant }}}=\frac{\rho_{\text {air }} \cdot S_{F r=1} \cdot v_{\text {air }}{ }^{2}}{\rho_{\text {pollu tant }} \cdot g \cdot V_{F r=1}}= \\
& =\frac{\rho_{\text {air }} \cdot l_{2, F r=1} \cdot l_{3, F r=1} \cdot v_{\text {air }}^{2}}{\rho_{\text {pollu tant }} \cdot g \cdot l_{1, F r=1} \cdot l_{2, F r=1} \cdot l_{3, F r=1}}
\end{aligned}
$$

or

$$
1=\frac{F_{I-\text { air }}}{F_{G-\text { pollu tant }}}=\frac{\rho_{\text {air }} \cdot v_{\text {air }}{ }^{2}}{\rho_{\text {pollu tant }, F r=1} \cdot g \cdot l_{1, F r=1}}
$$

Thus, $l_{1, F r=1}$ is

$$
\begin{gathered}
l_{1, F r=1}=\frac{\rho_{\text {air }} \cdot v_{\text {air }}{ }^{2}}{\rho_{\text {pollu tant }} \cdot g}=\frac{\rho_{\text {air }} \cdot v_{\text {air }}{ }^{2} \cdot l_{2, F r=1} \cdot l_{3, F r=1}}{\rho_{\text {pollu tant }} \cdot g \cdot l_{2, F r=1} \cdot l_{3, F r=1}}= \\
=\frac{\rho_{\text {air }} \cdot v_{\text {air }}{ }^{2} \cdot S_{F r=1}}{\rho_{\text {pollu tant }} \cdot g \cdot S_{F r=1}}
\end{gathered}
$$

The model scale $M_{F r=1}[-]$ for $F r=1$ (inertial and gravity forces are equal) is given by

$$
M_{F r=1}=\frac{1}{X}
$$

where

$$
X=\frac{l_{1}}{l_{1, F r=1}}
$$

The value $l_{1}$ represents the $1^{\text {st }}$ characteristic dimension of the pollutant source (length of pollutant cubic element) in the original model. The value $l_{1, F r=1}$ is the $1^{\text {st }}$ characteristic dimension of the pollutant source in the model where $F r=1$ (i.e., inertial and gravity forces are equal).

$$
F_{I 1}=X^{2} \cdot F_{I 2}
$$

The value $F_{I 1}$ is an inertial force of original pollutant cubic element and $F_{I 2}$ is an inertial force of scaled pollutant cubic element. If the model scale is changed, the change of the inertial force is given by

$$
F_{G 1}=X^{3} \cdot F_{G 2}
$$

The value $F_{G 1}$ is a gravity force of original pollutant cubic element and $F_{G 2}$ is a gravity force of scaled pollutant cubic element. The value $X$ is a model scale factor [-]. If $X>1$, the model is smaller than its original pattern (i.e., the model is downscaled). If $X<1$, the model is larger than its original pattern (i.e., the model is enlarged). Equations (11) and (12) are deduced from (1) for the Froude number.

A change in model scale always causes a change in the ratio of inertial and gravity forces. Therefore, some problems cannot be reliably modeled at other than approximately original scales. The range of deviation from the original depends on the discretion of investigators. Investigators must decide whether the tolerance of results is acceptable.

Modeling of gas pollutant plume motions with severely downscaled models is a typical example of this problem. Downscaled pollutant plume models will not correspond to the originally scaled patterns without modifying some key physical characteristics (air flow velocity, turbulent characteristics, etc.).

The problem can be solved by using a numerical mathematical model verified by a clearly defined experiment of the same type of physical phenomenon. Once the numerical model is verified, it can be used for numerical simulation of any problem of the same physical principles, whatever the model scale is. Sometimes it is impossible to do the same with a physical experiment.

It can be concluded that severely downscaled experiments are not suitable for modeling gas pollutant plume motions because of possible absence of vertical movements. It is more advisable to use physical experiment data only for verification of the numerical model (code, software).

\section{F. Example of CFD numerical simulation}

ANSYS Fluent 15.0, one of the world's most sophisticated CFD codes, was chosen for the numerical simulation of the gas pollutant plume motion and dispersion. The gauging section of the low-speed wind tunnel (length $2 \mathrm{~m}$, width $1.5 \mathrm{~m}$, height $1.5 \mathrm{~m}$, model scale $1: 1000$ ) with a small nozzle (diameter $0.0035 \mathrm{~m}$, height $0.02 \mathrm{~m}$, scale 1:1000) representing a chimney in a flat, simple terrain was the object of the numerical simulation. Gas pollutant enters the gauging section through the top of the nozzle (chimney) and is carried by flowing air (see Fig.2.).

RANS (Reynolds-averaged Navier-Stokes equations) approach was used for turbulent characteristics definition. The Boussinesq hypothesis of swirl turbulent viscosity was applied for the turbulent viscosity calculation. RNG $k-\varepsilon$ model of turbulence was used for the air flow field basic 
calculation (see [1], [2]). Species transport model was used for the species motion calculation. Both models worked simultaneously. No additional gas pollutant dispersion model was applied. The operating pressure was set at $101325 \mathrm{~Pa}$, the operating temperature was $300 \mathrm{~K}$, and the gravity acceleration was $-9.81 \mathrm{~m} / \mathrm{s}^{2}$ in the geometry. Considering the pollutant source close surroundings, the ranges of the Reynolds number $R e$ were 250-1250 [-] (model scale 1:1000, referential air flow velocity $1-5 \mathrm{~m} / \mathrm{s}$, and nozzle spout diameter $0.0035 \mathrm{~m}$ ) and 250000-1250000 [-] (model scale 1:1, referential air flow velocity $1-5 \mathrm{~m} / \mathrm{s}$, and chimney spout diameter $3.5 \mathrm{~m}$ ).

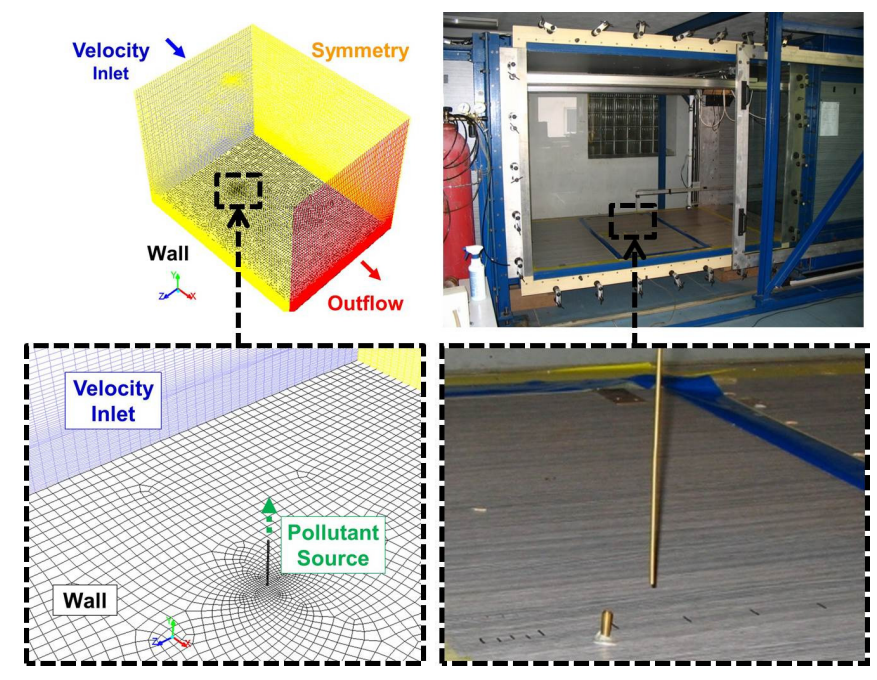

Fig.2. Geometry (gauging section of the low-speed wind tunnel) and pollutant source (numerical model versus physical experiment).

Boundary conditions were set to Velocity Inlet at the inlet, Outflow at the outlet, Wall for the floor, Symmetry for the walls, Wall for pollutant source walls, and Velocity Inlet for the nozzle (spout of the chimney).

Profiles of the flow field physical characteristics were determined at the inlet of the geometry (see Table 1.) based on experimental data from a low-speed wind tunnel for a 1:1000-scale model (see [3], [4], [5], [6], [11]). For other model scales, the profiles were modified to keep the trend of curves.

In Table 1. the parameter $v_{x}$ represents the air flow velocity in the direction of $\mathrm{X}$-axis $[\mathrm{m} / \mathrm{s}], I$ is the intensity of turbulence [\%], $Y$ is the vertical coordinate of the geometry $[\mathrm{m}], k$ is the turbulent kinetic energy $\left[\mathrm{m}^{2} / \mathrm{s}^{2}\right]$, and $\varepsilon$ is the turbulent dissipation rate $\left[\mathrm{m}^{2} / \mathrm{s}^{3}\right]$.

The pollutant source was designed as a nozzle (chimney). For all model scales, the pollutant velocity $v_{\text {pollu tan } t}$ was set at $0.5 \mathrm{~m} / \mathrm{s}$, the intensity of turbulence in the pollutant source at $10 \%$, the pollutant mass fraction in the pollutant source at $0.95[-]$ and the air mass fraction in the pollutant source at 0.05 [-]. The hydraulic diameter of the pollutant source was set at $3.5 \mathrm{~m}$ for $1: 1$-scale model, $0.866 \mathrm{~m}$ for $1: 4.04$-scale model, $0.0986 \mathrm{~m}$ for 1:35.51-scale model, $0.344 \mathrm{~m}$ for
$1: 101.821$-scale model, and $0.0035 \mathrm{~m}$ for $1: 1000$-scale model scale 1:1000.

Table 1. Air flow velocity profile and turbulent characteristics profiles in geometry [3], [4], [5], [11].

\begin{tabular}{|l|c|}
\hline $\begin{array}{l}\text { Vertical } \\
\text { profile }\end{array}$ & Equation \\
\hline $\begin{array}{l}\text { Air flow } \\
\text { velocity } \\
\text { (X-direct.) }\end{array}$ & $v_{x}=0.2371 \cdot \ln (Y+0.00327)+1.3571$ \\
\hline $\begin{array}{l}\text { Air } \\
\text { turbulent } \\
\text { intensity }\end{array}$ & $I=-0.0673 \cdot \ln (Y+0.00327)+0.1405$ \\
\hline $\begin{array}{l}\text { Turbulent } \\
\text { kinetic } \\
\text { energy }\end{array}$ & $k=1.5 \cdot\left(v_{x} \cdot I\right)^{2}$ \\
\hline $\begin{array}{l}\text { Turbulent } \\
\text { dissipation } \\
\text { rate }\end{array}$ & $\varepsilon=\frac{1.225 \cdot 0.09 \cdot\left(k^{3}\right)}{1.4}$ \\
\hline
\end{tabular}

Three different pollutants were chosen to be tested: helium, methanol and 1,2-dichlorethane. Helium ( $\rho=$ $\left.0.1625 \mathrm{~kg} / \mathrm{m}^{3}\right)$ has a lower density than air, i.e., it is lighter than air $\left(\rho=1.225 \mathrm{~kg} / \mathrm{m}^{3}\right)$. Methanol $\left(\rho=1.43 \mathrm{~kg} / \mathrm{m}^{3}\right)$ has approximately the same density as air, i.e., it is approximately of the same weight as air. 1,2-dichlorethane $\left(\rho=4.1855 \mathrm{~kg} / \mathrm{m}^{3}\right)$ has a greater density than air, i.e., it is heavier than air. Plumes of pollutants lighter than air tend to climb, whereas those heavier than air tend to descend. However, this is not always the case. Pollutant plume vertical movements can be influenced by several other physical factors as demonstrated in the analysis.

\section{RESULTS}

The results can be differentiated in three categories presented below.

\section{A. Analysis of results by air flow velocity}

The aim of this analysis is to compare gas pollutant plume shapes and motions for three different gas pollutants (helium, methanol and 1,2-dichlorethane) at different values of the air flow velocity $v_{\text {air }}$. The demonstration of the problem was performed with a 1:1-scale three-dimensional geometry representing the real pattern of a simple terrain with a chimney. The referential air flow velocities $v_{\text {air }}$ at the level of the chimney spout (pollutant source) were $1 \mathrm{~m} / \mathrm{s}$, $3 \mathrm{~m} / \mathrm{s}$ and $5 \mathrm{~m} / \mathrm{s}$.

Results were calculated using the ANSYS Fluent 15.0 software and were visualized in Fig.3. The contours were plotted in two-dimensional planes of the geometry, sc., the central vertical longitudinal plane, the floor (ground) plane, and the outlet plane.

The figure shows that with increasing air flow velocity $v_{\text {air }}$ the pollutant plume vertical movements are reduced. The pollutant plume inclines horizontally at the level of the 
chimney spout (pollutant source) showing no tendency to climb or descend. This is because the inertial force $F_{I \text {-air }}$ increases as the air flow velocity $v_{\text {air }}$ increases. Hence, the pollutant plume vertical movements are reduced or totally eliminated.

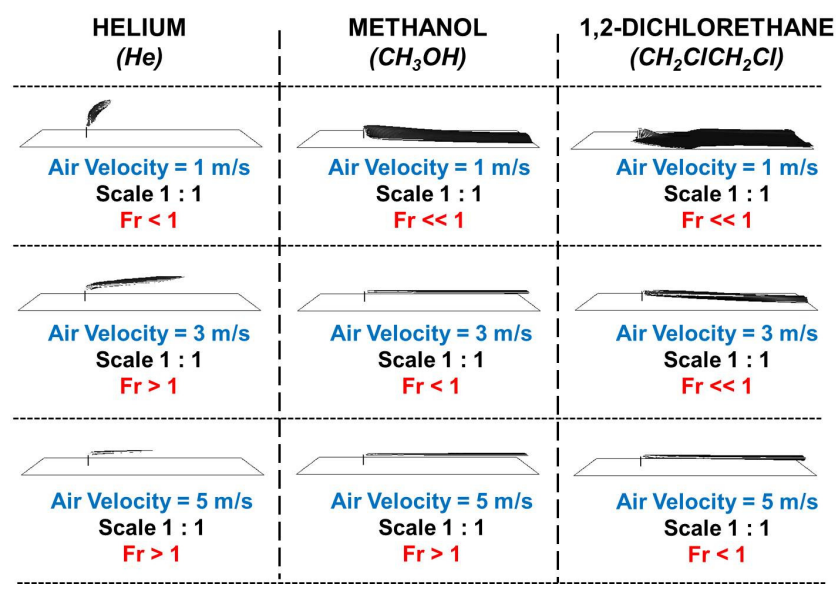

Fig.3. Gas pollutant plume motion analysis by air flow velocity and pollutant density (iso-surfaces of gaseous helium, methanol, and 1,2-dichlorethane concentrations with mass fraction of 0.0001 [-] for one model scale).

The air flow velocity also influences the size and shape of the pollutant plume. With increasing air flow velocity $v_{\text {air }}$ the pollutant plume tends to be narrower and longer. However, a further increase in the air flow velocity makes the pollutant plume shorter because of greater rate of the pollutant dispersion. The plume range at certain concentration of the pollutant therefore decreases with increasing air flow velocity.

\section{B. Analysis of results by pollutant density}

The aim of this analysis is to compare gas pollutant plume shapes and motions for three different gas pollutants (helium, methanol and 1,2-dichlorethane) at different values of their density. Demonstration of the problem was performed with a 1:1-scale three-dimensional geometry representing the real pattern of a simple terrain with a chimney. The referential air flow velocity $v_{\text {air }}$ at the level of the chimney spout (pollutant source) was $1 \mathrm{~m} / \mathrm{s}$.

Results were calculated using the ANSYS Fluent 15.0 software and were visualized in Fig.3. The contours were plotted in two-dimensional planes of the geometry, sc., the central vertical longitudinal plane, the floor (ground) plane, and the outlet plane.

The figure shows that: If the pollutant density $\rho_{\text {pollutant }}$ is lower than the air density $\rho_{\text {air }}$ the gas pollutant plume tends to climb (for helium see Fig.3.). If the pollutant density $\rho_{\text {pollutant }}$ is approximately the same as the air density $\rho_{\text {air }}$ the gas pollutant plume neither climbs nor descends (for methanol see Fig.3.). If the pollutant density $\rho_{\text {pollu tant }}$ is greater than the air density $\rho_{\text {air }}$ the gas pollutant plume tends to descend (for 1,2-dichlorethane see Fig.3.). The range of vertical movements is determined by gravity force $F_{G-\text { pollu tant }}$ that influences pollutant plume at given conditions. The greater the gravity force $F_{G-\text { pollu tant }}$ is compared to the inertial force $F_{I-\text { air }}$, the more significant is the vertical movement of the plume, i.e., light pollutant plume climbs and heavy pollutant plume descends.

The pollutant density $\rho_{\text {pollutant }}$ also influences the pollutant plume dispersion. The greater is the pollutant density, the longer is the range of the plume. At given air flow velocity $v_{\text {air }}$, the plume dispersion of pollutants with a low density is faster and easier than that of pollutants with a greater density.

\section{Analysis of results by model scale}

The aim of this analysis is to compare gas pollutant plume shapes and motions for three different gas pollutants (helium, methanol, and 1,2-dichlorethane) at different model scales. The demonstration of the problem was performed with a three-dimensional geometry at three selected scales for each of the three pollutants. The first 1:1-scale model represents the real pattern of a simple terrain with a chimney (pollutant source) where $F r<1$, i.e., the gravity force $F_{G-\text { pollutant }}$ is greater than the inertial force $F_{I-\text { air }}$. The second model (scaled at 1:4.04, 1:35.51, and 101.82, respectively) represents the state when $F r=1$, i.e., the gravity force $F_{G-\text { pollutant }}$ equals the inertial force $F_{I-\text { air }}$. The third 1:1000-scale model represents the gauging section of a low-speed wind tunnel with a nozzle (pollutant source) on the floor where $F r>1$, i.e., the inertial force $F_{I-\text { air }}$ is greater than the gravity force $F_{G-\text { pollutant }}$. The referential air flow velocity $v_{\text {air }}$ at the level of the chimney spout (pollutant source) was $1 \mathrm{~m} / \mathrm{s}$.

Results were calculated using the ANSYS Fluent 15.0 software and were visualized in Fig.4. Contours were plotted in two-dimensional planes of the geometry, sc. the central vertical longitudinal plane, the floor (ground) plane, and the outlet plane.

The figure shows that: If the model scale changes and all other characteristics remain unchanged, the inertial and gravity forces and their ratio change too. Therefore, the size, shape, and inclination of the pollutant plume change.

According to (11), the inertial force is proportional to the square of the model scale. According to (12), the gravity force is proportional to the third power of the model scale. Therefore, the change in the gravity force due to the change of the model scale is considerably greater than the change in the inertial force. The lower is the model scale, the greater is the dominance of inertial forces compared to gravity forces, and vice versa.

Also, the greater the pollutant density, the lower the model scale if $F r=1$, i.e., the inertial and gravity forces are equal. 


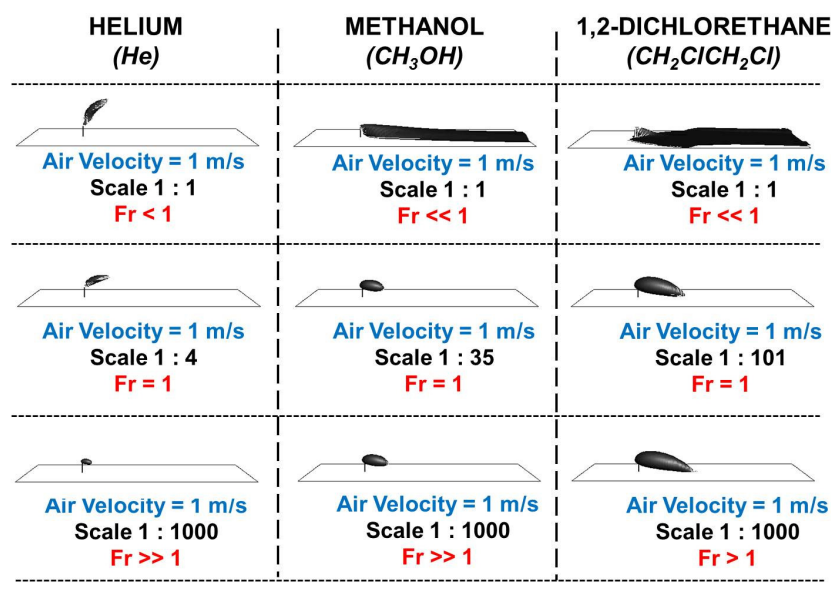

Fig.4. Gas pollutant plume motion analysis by model scale (isosurfaces of gaseous helium, methanol, and 1,2-dichlorethane concentrations with mass fraction of 0.0001 [-] for three different model scales).

\section{DISCUSSION / CONCLUSIONS}

The aim of the analyses was to lay down principles for physical and mathematical modeling of gas pollutant plume motion and dispersion in real atmospheric conditions. The influences of the air flow velocity, pollutant's density, and model scale on pollutant plume size, shape, and inclination were investigated.

The Froude number was chosen as a criterion of physical similarity for the pollutant plume behavior in the atmosphere. Basic mathematical rules and principles were formulated upon study of available fluid mechanics literature (see [7], [8], [9], [10], [11], [12], [13], [14]). Next, all mathematical and physical assumptions were verified by numerical simulation using the ANSYS Fluent 15.0 software. Air flow field was modeled using the RNG $k-\varepsilon$ model of turbulence, the gas pollutant motion was modeled using the Species Transport Model, both in the same threedimensional geometry consisting of 569490 grid cells. Turbulent characteristics were defined using RANS approach. No additional dispersion model was applied.

Object of modelling was gauging section of the low-speed wind tunnel (for model scale of 1:1000) or big real terrain (for model scale of 1:1) with a pollutant source in the form of a nozzle (or chimney, respectively) situated on the section floor (ground). The gauging section with the nozzle represented a chimney in a simple, flat terrain. The chimney was considered to be a pollutant source for three different gas pollutants (helium, methanol, and 1,2-dichlorethane). The numerical simulation was performed for five model scales, three gas pollutants with different densities, and three different air flow velocities. The simulations were steady (time-independent) with the accuracy of 0.0001 (criterion of convergence). Final results were visualized as pollutant concentration fields with the concentration limit value of 0.001 . The contours were plotted in two-dimensional planes of the geometry, sc. the central vertical longitudinal plane, the floor (ground) plane, and the outlet plane. The numerical model had been verified by an experiment performed in a low-speed wind tunnel (see [3], [4], [5]).

The following principles based on the results of the Froude number analysis of pollutant plume motion and dispersion in real atmosphere can be defined:

1) The greater is the air flow velocity, the greater are the inertial forces. These forces influence pollutant plume and reduce its vertical motions (inclination). With increasing air flow velocity, the pollutant plume inclines horizontally at the level of the chimney spout (pollutant source), but with further increase in the air flow velocity it becomes narrower and shorter.

2) The greater is the difference between pollutant density and air density, the more significant is the tendency towards vertical movements (climbing or descending) of the plume. The plume of pollutant with lower density than air tends to climb, whereas the plume of pollutant with greater density than air tends to descend. The density of the pollutant also influences the pollutant plume dispersion. The greater is the pollutant density, the longer is the range of the plume. At given air flow velocity $v_{\text {air }}$, the plume dispersion of pollutants with a low density is faster and easier than that of pollutants with a greater density.

3) If the model scale changes and all other characteristics remain unchanged, the inertial and gravity forces and their ratio change too. Therefore, the size, shape and inclination of the pollutant plume change. The inertial force is proportional to the square of the model scale, whereas the gravity force is proportional to the third power of the model scale. The change in the gravity force due to the change of model scale is considerably greater than the change in the inertial force. The lower is the model scale, the greater is the dominance of inertial forces compared to gravity forces. Also, the greater is the pollutant density, the lower is the model scale if $F r=1$, i.e., the inertial and gravity forces are equal.

\section{CONCLUSION}

From the above it follows that if investigators want to respect and follow the basics of physical phenomena, they must consider criteria of physical similarity very carefully, in particular criteria of dynamic similarity. Some physical phenomena, however, cannot be modeled in any model scale but the original one without changing the basis of the phenomena.

This analysis is intended for those who are interested in gas pollutant plume motion in the atmosphere and in theory of physical similarity. The conclusions of the analysis can be used for further experiment design works or for checking results of mathematical modeling.

\section{ACKNOWLEDGMENT}

Authors acknowledge the financial support of the SPII 1a10 45/07 project of the Ministry of the Environment of the Czech Republic. 


\section{REFERENCES}

[1] Kozubková, M. (2008). Modeling of Fluid Flow FLUENT, CFX. Ostrava, Czech Republic: VSB Technical University of Ostrava. (in Czech)

[2] Bojko, M. (2008). Guide for Training of Flow Modeling - FLUENT. Ostrava, Czech Republic: VSB Technical University of Ostrava. (in Czech)

[3] Civiš, S., Zelinger, Z., Střižík, M., Jaňour, Z. (2001). Simulation of air pollution in a wind tunnel. In Spectroscopy from Space: NATO Science Series IIMathematics Physics and Chemistry. Kluwer Academic Publishers, 275-299.

[4] Zelinger, Z., Střižík, M., Kubát, P., Jaňour, Z., Berger, P., Černý, A., Engst, P. (2004). Laser remote sensing and photoacoustic spectrometry applied in air pollution investigation. Optics and Lasers Engineering, 42 (4), 403-412.

[5] Zelinger, Z., Střižík, M., Kubát, P., Civiš, S., Grigorová, E., Janečková, R., Zavila, O., Nevrlý, V., Herecová, L., Bailleux, S., Horká, V., Ferus, M., Skřínský, J., Kozubková, M., Drábková, S., Jaňour, Z. (2009). Dispersion of light and heavy pollutants in urban scale models: $\mathrm{CO}_{2}$ laser photoacoustic studies. Applied spectroscopy, 63 (4), 430-436.

[6] Zavila, O., Herecová, L., Míček, D., Hejzlar, T. (2011). Numerical simulation of heavy and light pollutants motion as a tool of experimental data verification. Communications, 13 (2), 37-43.
[7] Čarnogurská, M., Přihoda, M. (2011). Application of Three-Dimensional Analysis for Modelling Phenomena in the field of Power Engineering. Kosice, Slovak Republic: Technical University of Kosice. (in Slovak)

[8] Incropera, F.P., Dewitt, D.P., Bergman, T.L., Lavine, A.S. (2007). Fundamentals of Heat and Mass Transfer. John Wiley \& Sons.

[9] Shaughnessy, E.J., Katz, M.I., Schaffer, J.P. (2005). Introduction to Fluid Mechanics. Oxford University Press.

[10] Drábková, S., Platoš, P. (2003). Numerical simulation as a tool for the solution and understanding of practical air pollution problems. In Proceedings of the Conference on Modelling Fluid Flow (CMFF'03). Budapest, Hungary: Budapest University of Technology and Economics.

[11] Stull, B.R. (1994). An Introduction to Boundary Layer Meteorology. Kluwer Academic Publishers.

[12] Caballero, R. (2014). Physics of the Atmosphere. IOP Publishing.

[13] Emeis, S. (2011). Surface-Based Remote Sensing of the Atmospheric Boundary Layer. Springer.

[14] Vallero, D.A. (2014). Fundamentals of Air Pollution (5th ed.). Academic Press.

Received November 18, 2016. Accepted February 6, 2017. 